\title{
CPR in COVID-19: Should We Use the PAPR to Keep the Savior Safe?
}

\author{
Sai Saran@ \\ Keywords: COVID-19, CPR, N95 respirators. \\ Indian Journal of Critical Care Medicine (2021): 10.5005/jp-journals-10071-23925
}

Cardiopulmonary resuscitation (CPR) in patients with coronavirus disease-19 (COVID-19) poses many challenges to the healthcare workers (HCWs) including, but not limited to, potentially reduced performance due to limitations imposed by respirators and other personal protective equipment (PPE), along with increased risk of infection due to aerosolization of viral particles. The abovementioned factors, in conjunction with poor survival rates post-CPR among patients with COVID-19, have even led few authors to debate the utility versus futility of CPR in such situations, as the safety of the HCWs is of paramount importance in the fight against this pandemic. ${ }^{1}$ Through this communication, we wish to express our concerns regarding respiratory protection of the HCWs involved in activities like CPR.

Firstly, N95 or equivalent respirators filtering face piece $\left(\mathrm{FFP}_{2}\right)$, which are offered to the HCWs need to be tested by "quantitative fit testing (QNFT)", rather than only "user seal check". ${ }^{2}$ QNFT measures the filtering efficacy of the respirator in various positions of face and neck, a likely scenario during activities like delivery of chest compression during CPR or endotracheal intubation. Unfortunately in real world scenario, respirators provided in many or most healthcare centers are of single size despite the well-known fact that "one size does not fit all". ${ }^{3}$ It is intuitive that such suboptimal protection makes $\mathrm{HCWs}$ vulnerable to infection especially during activities like CPR.

Furthermore, $\mathrm{FFP}_{2}$ or its equivalent respirators are tested at constant flow rates of 85 to $95 \mathrm{~L} /$ minute during the issue of standard certifications. However, during activities like delivery of chest compressions, far higher inspiratory flow rates are likely to be generated. ${ }^{2}$ Studies reveal that the peak inspiratory flow rates can increase significantly with activities like brisk walking (5-6 km/hour) on a tread mill, even going up to $414 \mathrm{~L} /$ minute. ${ }^{4}$ Increased flow rates have been proven to result in enhanced penetration of aerosol via respirators - a potential safety hazard during busy shifts in typical COVID ICUs. Further increase in the work of breathing while providing CPR or similar exertional activity could jeopardize the safety of HCWs.

Various interim guidelines have proposed modifications in CPR technique in patients with COVID-19 to ensure the safety of the HCWs, with particular emphasis on minimization of aerosol generation and exposure during the CPR. ${ }^{5}$ In addition to this, we propose to strongly consider urgent evaluation of powered air-purifying respirators (PAPR), which are unaffected by peak flow demands and offer minimal resistance to breathing needs, among the HCWs involved in CPR. PAPR is a respiratory protection device, wherein the HCW is in positive pressure (which serves to keep unfiltered ambient air from entering the headgear and being potentially breathed in by the user), being covered by a headgear receiving filtered air through a breathing tube, from the blower assembly fitted to the waist. The airflow levels can be adjusted based on the level of activity performed up to a maximum of $170 \mathrm{~L} /$ minute: "breath-response
Department of Critical Care Medicine, King George Medical University, Lucknow, Uttar Pradesh, India

Corresponding Author: Sai Saran, Department of Critical Care Medicine, King George Medical University, Lucknow, Uttar Pradesh, India, Phone: 8004505719, email: saisaranpv@gmail.com

How to cite this article: Saran S. CPR in COVID-19: Should We Use the PAPR to Keep the Savior Safe? Indian J Crit Care Med 2021;25(8):950.

Source of support: Nil

Conflict of interest: None

PAPR" (NIOSH 42 CFR 84.60 and 42 CFR 84.63). ${ }^{6}$ These provide a higher assigned protection factor (APF) between 25 and 1,000 with 96 to $99.9 \%$ filtration efficiency for $<0.3$ micron size particles, when compared to FFP2 or its equivalents with APF 10 and $95 \%$ filtration efficiency for $<0.3$ micron size particles. ${ }^{2,6}$ To conclude, policymakers and administrators must take concrete measures to ensure the safety of these saviours, to effectively continue fighting the pandemic.

\section{OrCID}

Sai Saran ำ https://orcid.org/0000-0002-6181-8661

\section{References}

1. Hayek SS, Brenner SK, Azam TU, Shadid HR, Anderson E, Berlin H, et al. In-hospital cardiac arrest in critically ill patients with covid-19: multicenter cohort study. BMJ 2020;371:m3513. DOI: 10.1136/bmj.m3513.

2. Saran S, Gurjar M, Baronia AK, Lohiya A, Azim A, Poddar B, et al. Personal protective equipment during COVID-19 pandemic: a narrative review on technical aspects. Expert Rev Med Devices 2020;17:1265-1276. DOI: 10.1080/17434440.2020.1852079.

3. Winter S, Thomas JH, Stephens DP, Davis JS. Particulate face masks for protection against airborne pathogens - one size does not fit all: an observational study. Crit Care Resusc 2010;12(1):24-27. PMID: 20196710

4. Holmér I, Kuklane K, Gao C. Minute volumes and inspiratory flow rates during exhaustive treadmill walking using respirators. Ann Occup Hyg 2007;51(3):327-335. DOI: 10.1093/annhyg/mem004.

5. Singh B, Garg R, Chakra Rao SC, et al. Indian resuscitation council (IRC) suggested guidelines for comprehensive cardiopulmonary life support (CCLS) for suspected or confirmed coronavirus disease (COVID-19) patient. Indian J Anaesth 2020;64:91. DOI: 10.4103/ija.IJA_481_20.

6. Board on Health Sciences Policy; Institute of Medicine. The use and effectiveness of powered air purifying respirators in health care: Workshop summary. Washington (DC): National Academies Press (US); 2015 May 7. 2, Defining PAPRs and Current Standards. Available from: https://www.ncbi.nlm.nih.gov/books/NBK294223/. 